\title{
Role of Disodium Cromoglycate ('Intal') in Treatment of Childhood Asthma
}

\author{
R. S. JONES and M. I. BLACKHALL \\ From the Institute of Child Health, University of Liverpool, and Alder Hey Children's Hospital, \\ Liverpool
}

Jones, R. S., and Blackhall, M. I. (1970). Archives of Disease in Childhood. 45, 49. Role of disodium cromoglycate ('Intal') in treatment of childhood asthma. The clinical and physiological responses to disodium cromoglycate have been examined in 77 children with asthma.

Those in whom definite clinical benefit was observed were the highly labile (Group 2) subjects with normal or near normal ventilatory function between attacks. $60 \%$ of these responded well and since they constitute $80 \%$ of children with asthma who attend hospital, approximately half of those children may be expected to benefit. The response in the severe (Group 3) asthmatics, with impairment of function between attacks, was poor, only one-quarter deriving benefit.

Disodium cromoglycate is not indicated in mild (Group 1) asthma.

Disodium cromoglycate is a valuable drug in the treatment of childhood asthma in suitably selected subjects. No important side-effects or tissue reactions have been observed.

There have recently been a number of favourable reports following clinical trials of disodium cromoglycate in the treatment of asthma (Howell and Altounyan, 1967; Kennedy, 1967; Morrison Smith and Devey, 1968). Grant, Channell, and Drever (1967) reported unfavourably, and Moran, Bankier, and Boyd (1968) found that in a total of 21 patients from 11 to 66 years the drug was more valuable in patients under 50 years of age and without bronchitic symptoms. Kidner et al. (1968) found its action less impressive, $38 \%$ of their patients showing improvement. Morrison Smith and Devey (1968) reported a trial in childhood asthma in which they found improvement in $54 \%$ of 44 patients.

There can be little doubt that disodium cromoglycate is of value, but since only about one-half of subjects benefit, it is presumably more effective in some types of asthma than others. The object of this paper is to offer physiological and clinical evidence to indicate which patients benefit and how the drug should be used alongside other methods of treatment.

\section{Methods}

Measurements of FEV ( 1 sec.) and FVC were made with a Lode spirometer in investigation (1) and a modified Gaensler spirometer in investigations (2) and (3).

Received 18 June 1969.
Measurement of lability was performed according to Jones (1966), using the formula:

Lability index $=$

Fall of FEV in litres + Rise of FEV in litres $\frac{\text { Predicted normal FEV at rest }}{\text { nat }} \times 100$,

where (1) 'Fall of FEV' refers to the difference between the value at rest and the lowest value following an 8-minute standard exercise test. (2) 'Rise of FEV' refers to the difference between the value at rest and the highest value after bronchodilatation, with isoprenaline sulphate $1 \%$ given as an aerosol for 2 minutes through a Wright inhaler at $81 . / \mathrm{min}$. flow, followed by a standard 1-minute exercise period.

Exercise was performed by running along a horizontal corridor for investigations (1), (2), and (3). It was considered essential to standardize the form of exercise for each project in order to avoid inconsistent results. Running up or down stairs and the use of a bicycle ergometer were regarded by us as unsatisfactory because they do not produce repeatable results. Only one measurement of lability was made on any particular day as repetition may produce false results.

The classification of asthma used is set out in Table $I$.

Lung volume measurements were made using a closed circuit spirometer system with helium katherometer and $\mathrm{CO}_{2}$ absorber incorporated in the circuit.

Specific compliance was measured by applying a weight to the bell of the closed circuit machine, measuring the change in resting respiratory level, and expressing the result as total compliance per litre of lung volume (Cherniack and Brown, 1965). 
TABLE I

Classification of Asthma (Jones, 1966)

\begin{tabular}{c|c|c}
\hline Group & Max. FEV1.0 & Lability \\
\hline 1 & $\mathrm{~N}$ & $15-30 \%$ \\
2 & $\mathrm{~N}$ & $>30 \%$ \\
$3^{\star}$ & $<\mathrm{N}$ & Variable \\
Normal & $\mathrm{N}$ & $<20 \%$ \\
\hline
\end{tabular}

^These subjects have a fixed increase of airway resistance, which obscures the labile component. Hence it is variable and usually less than in Group 2.

Volumes were corrected in all experiments to body temperature and ambient pressure saturated.

Disodium cromoglycate was administered in accordance with the maker's instructions. The preparation used throughout was the one which did not contain isoprenaline sulphate. *

Investigation (1) - 4-day trial. Disodium cromoglycate was given for 4 days in a dose of 4 capsules per day to 11 children aged 6 years to 17 years (Table II).

\section{TABLE II}

Effect of Disodium Cromoglycate for 4 days on Ventilatory Function in 11 Asthmatic Children

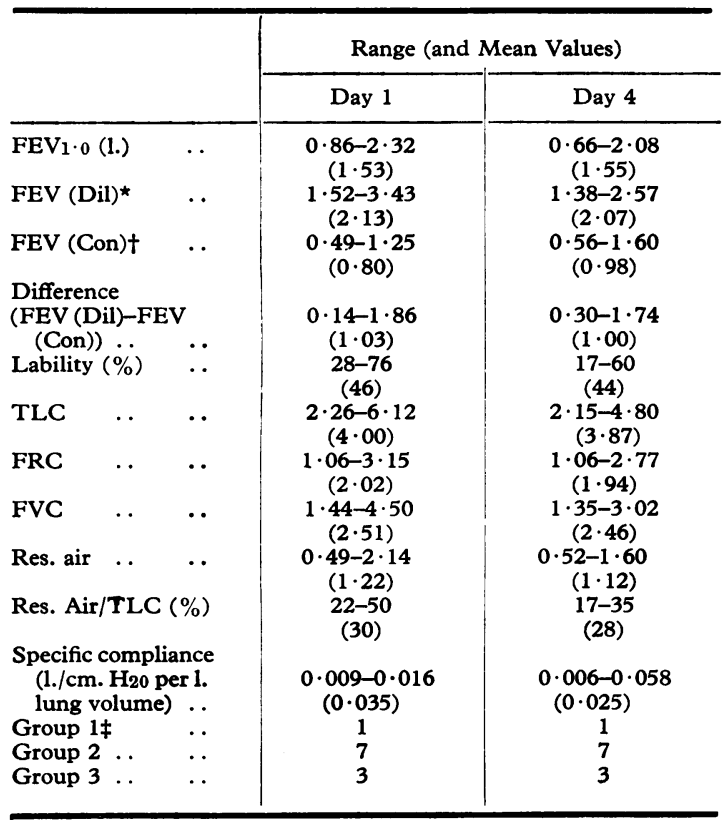

^FEV (Dil)-FEV after maximum bronchodilatation with isoprenaline sulphate and 1 minute exercise.

tFEV (Con)-Lowest value after 8 minutes exercise.

¥Classification, Table $\mathrm{I}$.

*The drug was kindly supplied by Messrs. Fisons Ltd., of Loughborough.
FEV, FVC, lability, specific compliance, and lung volume measurements were made before and after this interval of time. Measurements were not made within two hours of taking a capsule, so the results reflect the sustained effect of the drug and not the immediate short-term effect which has been reported elsewhere (Blackhall and Jones, 1969). Values for each parameter at the beginning and end of the 4-day period were compared using Student's ' $t$ ' test by the method of difference.

Investigation (2)-2-month trial. Eight children were given disodium cromoglycate, 4 capsules per day for a month, and were then changed to placebo. A further 8 children were given 4 placebo capsules daily for 1 month, and then disodium cromoglycate for 1 month over the same period as the first group. The subjects were not aware of which was placebo and which disodium cromoglycate, but 3 thought that disodium cromoglycate was more effective and one that the placebo was more effective. The remaining 12 were unaware of any difference.

The FEV at rest was measured and significance was tested using Student's ' $t$ ' test by the method of difference.

Investigation (3)-20-month trial. Fifty children on 4 capsules of disodium cromoglycate daily were observed for $\mathbf{2 0}$ months. Additional treatment was given as indicated by the clinical state. Patients were examined clinically beforehand and also classified into one of the three groups shown in Table I. Skin tests were performed for evidence of sensitivity to common allergens. At the end of the investigation they were divided into those who derived clear benefit from disodium cromoglycate, those in whom benefit was doubtful, and those who derived no benefit.

These decisions were based upon statements made by the child and the parent, and observations made by the clinician (number and severity of attacks, loss of schooling, and physical signs). No attempt was made to make the investigation 'blind', but the clinician was not aware of the physiological grouping at the time of the assessment. Differences were examined by the $\chi^{2}$ test.

\section{Results}

(1) 4-day trial. There was no significant difference between the results at the beginning and end of the 4-day period for any of the parameters examined $(p>0.05)$ (Table II). The difference between the maximally dilated and constricted figures at the beginning and end of the 4-day period reflect lability, and the absence of a significant difference suggests little sustained effect.

One subject classified as Group 3 on day 1 was classified 2 at the end, but in another subject the reverse occurred.

(2) 2-month trial. There was no significant difference between FEV at the beginning and end 
of each period for the placebo/active group and the active/placebo group. 4 subjects in each group were considered to have derived clinical benefit. When these were grouped together and compared with the 'no benefit' group, there was still no significant difference. Half of the subjects were in Group 2 and half in Group 3. No subject moved into another group during the trial.

(3) 20-month trial. The results are shown in Table III. Of the Group 2 subjects, $60 \%$ derived

TABLE III

Response of 50 Patients to Disodium Cromoglycate

\begin{tabular}{|c|c|c|c|c|c|}
\hline \multirow[b]{2}{*}{$\begin{array}{l}\text { Definite benefit .. } \\
\text { Doubtful benefit .. } \\
\text { No benefit }\end{array}$} & \multicolumn{2}{|c|}{ Group 2 (35) } & \multicolumn{2}{|c|}{ Group 3 (15) } & \multirow{2}{*}{$\begin{array}{c}\text { Total } \\
25 \\
25\end{array}$} \\
\hline & $\left.\begin{array}{c}21 \\
6 \\
8\end{array}\right\}$ & $\begin{array}{l}(60 \%) \\
(40 \%)\end{array}$ & $\left.\begin{array}{l}4 \\
4 \\
7\end{array}\right\}$ & $\begin{array}{l}(27 \%) \\
(73 \%)\end{array}$ & \\
\hline Total & 35 & & 15 & & 50 \\
\hline
\end{tabular}

benefit as compared with $27 \%$ of the Group 3 subjects. This difference is significant $(0.05>p$ $>0.02$ ); only 4 out of 15 Group 3 subjects derived benefit. It is concluded that the beneficial effects of disodium cromoglycate are due primarily to its action in Group 2 asthma.

Skin allergy. Of the 50 subjects, 44 had been skin tested to common allergens. Of the 21 exhibiting significant skin reactions, 8 had a favourable and 13 an unfavourable response to disodium cromoglycate.

Of 23 with negative skin reactions, 12 had a favourable and 11 an unfavourable response to disodium cromoglycate.

It is concluded that there is no relation between hypersensitivity as measured by skin tests and the clinical response to disodium cromoglycate.

Group 2 asthma. Of the 14 subjects in whom benefit was absent or doubtful, 6 needed additional therapy with ACTH and/or steroid (Table IV) during the period of the trial. Of the 21 Group 2 subjects who derived benefit, 6 had been continuously or were occasionally on steroid or ACTH, and in these it was possible to reduce or discontinue it. The remaining 15 in this group were having troublesome attacks which were not sufficiently severe to merit steroid, but did not respond satisfactorily to bronchodilator agents. They responded well to disodium cromoglycate.

Group 3 asthma. Of 11 who did not benefit, 8 needed additional therapy with ACTH or steroid
TABLE IV

Response of 35 Group 2 Subjects to Disodium Cromoglycate

\begin{tabular}{l|c|c}
\hline Therapy & Benefit & No benefit \\
\hline Steroid/ACTH _. & 6 & 6 \\
No steroid/ACTH & 15 & 8 \\
\hline
\end{tabular}

during the period of the trial (Table $\mathrm{V}$ ). Of the 4 who did benefit, only 1 had required steroid.

No significant side-effects or toxic reactions were observed in any of the patients treated. No significant bronchoconstrictor effects of disodium cromoglycate were noted with the preparation which does not contain isoprenaline sulphate.

TABLE V

Response of 15 Group 3 Subjects to Disodium Cromoglycate

\begin{tabular}{c|c|c}
\hline Therapy & Benefit & No Benefit \\
\hline Steroid/ACTH $\ddot{1}$ & 1 & 8 \\
No steroid/ACTH & 3 & 3 \\
\hline
\end{tabular}

\section{Discussion}

Previous clinical trials already referred to have shown that the response to disodium cromoglycate is by no means uniform and that approximately $50 \%$ of patients derive benefit. The reason for lack of uniformity of clinical response is not clear. The physiological evidence is also conflicting. Altounyan (1965) and Pepys et al. (1968) showed that patients exposed to pollen could be protected against bronchoconstriction by disodium cromoglycate. On the other hand, Herxheimer and Bewersdorff (1969), in similar experiments using aqueous extracts of antigenic material administered in the form of an aerosol, reported protection in only 2 of 13 patients and possible protection in a further 3 .

These discrepancies may be explained to some extent by considering the degree to which ventilatory impairment in a given subject is due to the fixed and labile components of airway resistance, (Jones, 1966). The fixed component is due primarily to mucosal swelling and luminal obstruction caused by an allergic response of the mucosa with or without superimposed infection. This component predominates in the severe, Group 3, asthmatic, and the only agents that materially affect it are steroids, ACTH, and antibiotics. On the other hand, in Groups 1 and 2 asthmatics the labile component predominates and is presumed to be controlled chiefly by a neuromuscular 
mechanism which responds to a different set of drugs, the various bronchodilator agents. The evidence presented here suggests that disodium cromoglycate affects the labile rather than the fixed component.

One index of lability is the degree to which bronchoconstriction occurs after exercise. Davies (1968) showed that the post-exercise fall of FEV was reduced in all of the 8 subjects he examined when one capsule of disodium cromoglycate was taken a quarter of an hour before exercise. Unfortunately, this exercise test took the form of running up and down stairs, which gives inconsistent results. In addition, since the two tests should not be done on the same day, and since resting values in the asthmatic subject may vary widely from day to day, the interpretation of these results is rendered difficult.

We have shown the following elsewhere (Blackhall and Jones, 1969):

(1) In order to avoid these errors, measurements of the effect of exercise may be made by comparing the slopes of the lines representing the post-exercise fall of FEV.

(2) There is a significant increase in the slope at half an hour $(0.01>p>0.002)$ and at one hour $(0.05>p>0.002)$, indicating a diminished postexercise fall when two capsules of disodium cromoglycate are given either half or one hour before the exercise. This effect was shown, however, in only 11 out of the 16 subjects tested.

(3) The sixteen subjects were specially selected so that there was a group of 8 who had shown clearcut clinical benefit from disodium cromoglycate and 8 who had not derived benefit. There was a significant positive correlation between clinical benefit and reduction of post-exercise bronchoconstriction. Out of the 8 who had derived no benefit there were 4 Group 3 and 4 Group 2 patients, whereas of the 8 who had derived benefit there was 1 Group 3 and 7 Group 2 patients.

(4) The action of disodium cromoglycate as measured by this technique is probably sustained for no longer than 2 hours.

Further evidence on the relation between lability and the response to disodium cromoglycate is reported here in the 20 months trial. Exactly $50 \%$ of the whole group of 50 subjects obtained a favourable clinical response, which is the order of benefit reported elsewhere. Only one-quarter of those in Group 3 obtained a satisfactory response, whereas $60 \%$ of those in Group 2 did so. It is clear, therefore, that the labile asthmatic (Group 2) is much more likely to benefit than the Group 3 asthmatic, who is the severe asthmatic with persis- tent symptoms and frequent attacks. $\mathrm{He}$ is very likely to have received steroid and/or ACTH therapy in the past. If disodium cromoglycate is used in this group the probability is, therefore, that additional treatment will be required in order to obtain a satisfactory response.

Group 3 subjects tend to be resistant to treatment in the sense that ventilatory function may not return to normal. Even if normal function is not achieved, however, the response to a drug may be of clinical value if it results in greater stabilization, because it is not simply the low level of ventilatory function which upsets these subjects, but the fact that the level fluctuates. From Table V it can be seen that 3 out of 6 Group 3 subjects who were not on steroid or ACTH derived benefit. In these milder Group 3 subjects therefore, disodium cromoglycate may be worth trying as a means of stabilizing ventilatory function.

The failure rate of $40 \%$ is still appreciable in Group 2, though these are asthmatics with high lability in whom symptoms are primarily due to the labile component of airways resistance. Those who respond best have clear-cut attacks of asthma every one to two weeks with normal or near normal ventilatory function between, no associated infection, and an unimportant psychological component. A clear-cut clinical history of allergy, together with evidence of skin sensitivity, does not influence the likelihood of a satisfactory response to disodium cromoglycate. Group 2 patients in whom severe attacks have led to the use of steroid or ACTH may well manage with disodium cromoglycate alone, or with a smaller dose of steroid or intermittent steroid.

Other Group 2 subjects tend to have impaired ventilatory function at rest between attacks and may respond poorly to disodium cromoglycate.

In some of these there is a conspicuous psychological or infective component, which probably accounts for the lack of response. It is probably these factors that largely account for the $40 \%$ failure rate.

A small proportion of Group 2 subjects have quite severe attacks spaced at relatively long intervals of a month or more, who are otherwise remarkably symptom free and have good ventilatory function. Disodium cromoglycate tends to be less satisfactory in this group, many of whom are found to respond better to short courses of steroid started early in the attack.

The significance of the negative results of investigations (1) and (2) (4-day and 2-month trial) reported is uncertain. The methods used may have been too insensitive to detect small changes, 
but if this is so, the clinical benefit achieved could hardly be due to such small effects. Though a transient reduction in lability has been shown after inhalation of disodium cromoglycate (Blackhall and Jones, 1969), the clinical effects are probably due to a smaller, unmeasurable but sustained effect on lability which results in stabilization of the level of ventilatory function. Stabilization, whether it be produced by a drug such as disodium cromoglycate, by desensitization, or by psychotherapy, is as important to the asthmatic as improvement in the over-all level of ventilatory function. It follows that we cannot agree with the conclusion of Herxheimer and Bewersdorff, (1969) that disodium cromoglycate is unlikely to be of clinical value simply because the physiological responses of their patients were largely negative: little significance can be attached to results from a small series of 13 patients of unspecified age, whose clinical response is not reported and ventilatory status largely unknown.

\section{REPERENCES}

Altounyan, R. E. C. (1965). Summary of Information on FPL 670. Fisons.

Blackhall, M. I., and Jones, R. S. (1969). Effect of disodium cromoglycate on post exercise bronchoconstriction in asthma. Proceedings of Symposium on Disodium Cromoglycate in Allergic
Airways Disease. Royal Society of Medicine Symposium, Butterworth, London.

Cherniack, R. M., and Brown, E. (1965). A simple method for measuring total respiratory compliance: normal values for males. Fournal of Applied Physiology, 20, 87.

Davies, S. E. (1968). Effect of disodium cromoglycate on exerciseinduced asthma. British Medical fournal, 3, 593.

Grant, I. W. B., Channell, S., and Drever, J. C. (1967). Disodium cromoglycate in asthma. Lancet, 2, 673.

Herxheimer, H., and Bewersdorff, H. (1969). Disodium cromoglycate in the prevention of induced asthma. British Medical fournal, 2, 220.

Howell, J. B. L and Altounyan, R. E. C. (1967) A double-blind trial of disodium cromoglycate in the treatment of allergic bronchial asthma. Lancet, 2, 539.

Jones, R. S. (1966). Assessment of respiratory function in the asthmatic child. British Medical fournal, 2, 972.

Kennedy, M. C. S. (1967). Preliminary results of a double-blind cross-over trial on the value of FPL 670 in the treatment of asthma. Acta Allergologica, 22, 487.

Kidner, P. H., Meisner, P., Pride, N. B., and Bruce Pearson, R. S. (1968). Disodium cromoglycate in the treatment of bronchial asthma. Lancet, 2,655 .

Moran, F., Bankier, J. D. H., and Boyd, G. (1968). Disodium cromoglycate in the treatment of allergic bronchial asthma. ibid., $2,137$.

Morrison Smith, J., and Devey, G. F. (1968). Clinical trial of disodium cromoglycate in treatment of asthma in children. British Medical fournal, 2, 340.

Pepys, J., Hargreave, F. E., Chan, Moira, and McCarthy, D. S. (1968). Inhibitory effects of disodium cromoglycate on allergeninhalation tests. Lancet, $2,134$.

Correspondence to Dr. R. S. Jones, Alder Hey Children's Hospital, Eaton Road, Liverpool L12 2AP. 